\title{
Stochastic integrated vendor-buyer model with unstable lead time and setup cost
}

\author{
Chandra K. Jaggi ${ }^{\text {** }}$ and Neetu Arneja ${ }^{a}$ \\ ${ }^{a}$ Department of Operational Research Faculty of Mathematical Sciences, New Academic Block, University of Delhi, Delhi - 110007, India
}

\begin{tabular}{l} 
A R T I C L E I N F O \\
\hline Article history: \\
Received 6 July 2010 \\
Received in revised form \\
30 August 2010 \\
Accepted 1 September 2010 \\
Available online \\
2 September 2010 \\
\hline Keywords: \\
Inventory \\
Setup cost \\
Lead-time \\
Crashing cost \\
supply chain
\end{tabular}

\begin{abstract}
A B S T R A C T
This paper presents a new vendor-buyer system where there are different objectives for both sides. The proposed method of this paper is different from the other previously published works since it considers different objectives for both sides. In this paper, the vendor's emphasis is on the crashing of the setup cost, which not only helps him compete in the market but also provides better services to his customers; and the buyer's aim is to reduce the lead time, which not only facilitates the buyer to fulfill the customers' demand on time but also enables him to earn a good reputation in the market or vice versa. In the light of the above stated facts, an integrated vendor-buyer stochastic inventory model is also developed. The propsed model considers two cases for demand during lead time: Case (i) Complete demand information, Case (ii) Partial demand information. The proposed model jointly optimizes the buyer's ordered quantity and lead time along with vendor's setup cost and the number of shipments. The results are demonstrated with the help of numerical examples.
\end{abstract}

\section{Introduction}

With the advent of globalization of markets, it has been observed that mutual coordination between vendor-buyer system is more profitable as compared to their individual systems and one of the major concerns is the integration of the vendor-buyer inventory system. As in the supply chain system, the main objective of the vendor and the buyer is to minimize the joint total expected cost. Goyal (1976) is believed to be the first who introduced the concept of the joint optimization. Later, Banerjee (1986) investigated the model with the assumption that the vendor manufactures at a finite rate and considered a lot for lot model. Ha and Kim (1997) discussed about the integrated just-in-time (JIT) lot-splitting model for smoothing the progress by using multiple shipments in small lots. Many researchers (Goyal, 1995; Goyal \& Nebebe, 2000; Lu, 1995; Hill, 1999) already discussed various models with distinct policies of shipments between the vendor and the buyer. But, the focus was mostly on the production shipment schedule between both parties concerning size and frequency of order under the deterministic scenario i.e. when the lead time and demand are known.

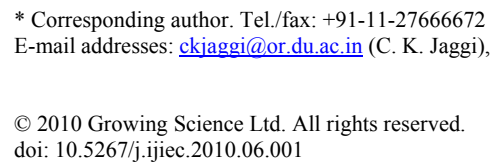


Recently, various researches have proposed integrated inventory models involving variable lead time. Ben-daya and Hariga (2004) examined the integrated single vendor single buyer model with stochastic demand and variable lead time for buyer. Chang et al. (2006) extended their model by taking the crashing of ordering cost for the buyer, where lead time and ordering cost are linearly dependent. There are also some integrated inventory model involving variable lead time with quality improvement (Yang \& Pan, 2004; Ouyang et al., 2002; Ouyang et al., 2007; Hoque, 2007; Nasri, 1990). Unfortunately, none of them considered the reduction of setup cost for the vendor which helps speed up the production process/delivery of the orders.

JIT suggests that the reduction of setup cost and lead time is possible by investing extra capital, since various efforts such as worker training, procedural changes and specialized equipment not only facilitate the reduction of the setup cost, but also improve the working of the running system. This eventually helps the firm reduce its total cost for the long run. Porteus (1985) stuied the impact of capital investment in reducing setup costs on the classical economic order quantity (EOQ) model. Thereafter, many researchers reported several relationships between the amount of capital investment and setup cost level (Nori and Sarker, 1996; Kim et al., 1992; Trevino et al., 1993; Sarker and Coates, 1990). Most of these scholars assume the logarithmic function for the investment. Furthermore, the JIT philosophy also advocates in favor of comparatively low lead times to order the small lot sizes. Tersine (1994) suggested that the favorable lead time is composed of different components viz. order preparation, order transit, supplier lead-time, delivery time and setup time. Thus, it is completely possible to crash these components at an extra cost. Usually, the extra cost of reducing the lead-time consists of administration, transportation and the supplier's speed up costs etc. Liao and Shyu (1991) presented a probabilistic inventory model in which the order quantity was predetermined and leadtime was unique decision variable, which was further extended by Ben-Daya and Raouf (1999) with the consideration of the lead time and the ordering quantity as decision variables without consideing any shortages. Since then, different authors have presented the stochastic inventory models with leadtime reduction (Moon \& Choi, 1998; Hariga \& Ben-Daya, 1999; Chuang et al., 2004). In all these articles, the authors concentrated on the benefits driven by reduction of lead time/setup cost, either for the vendor or for the buyer. But none of them investigated the situation where vendor's and buyer's objectives are different. Vendor is normally interested in reducing his setup/ordering cost and buyer's emphasis is on lead time reduction or vice versa. Added to this is the subsequent exploration of how JIT philosophy is useful to both the vendor as well as the buyer. In this paper, an integrated vendorbuyer inventory model is considered. Two cases for demand during lead time are discussed: case (i) Complete demand information and case (ii) Partial demand information. The model jointly optimizes the buyer optimal order quantity, lead time and setup cost, and number of shipments for the vendor. Findings are also validated with the help of examples along with the sensitivity analysis on the backorder ratio $(\beta)$.

\section{Notations and Assumptions}

\subsection{Notations}

$D:$ Average demand per year at the buyer

$A_{b}:$ Buyer's ordering cost per order

$A_{v}:$ Vendor's Setup cost per setup

$L$ : Length of lead-time

$r$ : Reorder point of the buyer

$h_{v}$ : Holding cost per unit per year for the vendor 
$h_{b}$ : Holding cost per unit per year for the buyer

$p \quad$ : Buyer's unit shortage cost per unit short

$p_{0}:$ Buyer's marginal profit per unit

$m$ : The number of shipments in one production cycle, a positive integer

$\beta$ : Fraction of the demand during the stock out period will be backordered, $\beta \in[0,1]$

$Q \quad$ : Lot size (order quantity)

$P \quad:$ Production rate at the vendor

$X$ : A random variable represents lead-time demand with mean $D L$ and standard deviation $\sigma \sqrt{L}>0$,

$E($.$) : Mathematical expectation$

$x^{+}$: Maximum value of $x$ and 0 ; i.e. $x^{+}=\max \{x, 0\}$

\subsection{Assumptions}

1. The product is manufactured with a finite production rate $P$ with $P>D$.

2. Inventory is continuously reviewed and buyer places the order whenever the inventory level falls to the reorder point $r$. The reorder point $r$ is equal to expected demand during lead-time plus safety stock, that is $r=D L+k \sigma \sqrt{L}$ where $k$ is a safety factor.

3. The setup cost $A_{V}$ for the vendor consists of $m$ mutually independent components. The $\mathrm{j}^{\text {th }}$ component has a normal cost $e_{i}$ and minimum cost $d_{i}$ and a crashing cost $f_{i}$ when the normal cost reduces to minimum cost. Arranging $f_{i}$ such that $f_{1} \leq f_{2} \leq f_{3} \ldots \leq f_{m}$, crashing of setup cost starts from its first component as it acquires the minimum unit crashing cost, then component 2 and so on.

4. Let $A_{V 0}=\sum_{i=1}^{m} e_{i}$ be the total normal setup cost without crashing and $A_{V j}$ be the reduced set up cost when ' $j$ ' components crashed to their minimum cost, where $j=1,2, \ldots, m$ and given as $A_{V j}=A_{V 0}-\sum_{i=1}^{j}\left(e_{i}-d_{i}\right), i=1,2, \ldots, m$ and setup crashing cost per cycle $R\left(A_{V j}\right)$ is given as $R\left(A_{V j}\right)$ $=\sum_{i=1}^{j} f_{i}$ (Cheng et al., 2004).

5. The lead-time $L$ for the buyer consists of $n$ mutually independent components. The $i^{\text {th }}$ component has a minimum duration $a_{i}$ and normal duration $b_{i}$, and a crashing cost per unit time $c_{i}$, such that $c_{1} \leq c_{2} \leq c_{3} \ldots \leq c_{n}$. Crashing of lead time starts from its first component as it acquires the minimum unit crashing cost and then component 2 then component 3 and so on.

6. Let $L_{0}=\sum_{j=1}^{n} b_{j}$ be the total normal lead time without crashing and $L_{i}$ be the length of lead time when ' $i$ ' components are crashed to their minimum duration, then $L_{i}$ can be expressed as 
$L_{i}=L_{0}-\sum_{j=1}^{i}\left(b_{j}-a_{j}\right), i=1,2, \ldots, n$ the lead time crashing cost per cycle is given as $C\left(L_{i}\right)=$ $c_{i}\left(L_{i-1}-L\right)+\sum_{j=1}^{i-1} c_{j}\left(b_{j}-a_{j}\right)$.

7. The buyer places an order of size $Q$ and the vendor produces $m Q$ with a finite production rate at one setup to reduce the production cost, but ship quantity $Q$ to the buyer over $m$ times. The vendor incurs setup cost $A_{v}$ for each production run and the buyer incurs an ordering cost $A_{b}$ for each order of quantity $Q$.

\section{Mathematical Model}

An integrated single vendor-single buyer inventory model for a single commodity is considered. The buyer's cost and vendor' cost are as follows.

\subsection{Buyer Cost}

In a continuous review system, inventory is monitored continuously and the buyer places the order as soon as his inventory level reaches the reorder point $r$, where $r=D L+k \sigma \sqrt{L}$. Let $X$ be the lead time demand with mean $D L$ and standard deviation $\sigma \sqrt{L}$, then, the expected shortage at the end of the cycle is given by $E(X-r)^{+}$i.e. $E(X-r)^{+}=\int_{r}^{\infty}(X-r) f_{X} d x$. The expected number of backorders per cycle is given by $\beta E(X-r)^{+}$with $(1-\beta) E(X-r)^{+}$as the number of lost sale. Thus, the expected net inventory before the order arrives is $\left(r-D L+(1-\beta) E(X-r)^{+}\right)$and the expected net inventory level after the successive shipment is $\left(Q+r-D L+(1-\beta) E(X-r)^{+}\right)$. Therefore, the expected holding cost per year is $h_{b}\left[Q / 2+r-D L+(1-\beta) E(X-r)^{+}\right]$.

The total expected annual cost (EAC) for the buyer consists of the ordering cost, the units holding cost, the stock out cost, and the lead time crashing cost given as follows,

$$
E A C_{b}(Q, L)=\left(A_{b} / T\right)+h_{b}\left[Q / 2+r-D L+(1-\beta) E(X-r)^{+}\right]+\frac{\left[p+p_{0}(1-\beta)\right] E(X-r)^{+}}{T}+\frac{C\left(L_{i}\right)}{T} .
$$

Since $T=Q / D$, then, the Eq. (1) is reduced to the following,

$$
E A C_{b}(Q, L)=\frac{A_{b} D}{Q}+\frac{h_{b} Q}{2}+h_{b}\left[r-D L+(1-\beta) E(X-r)^{+}\right]+\frac{D\left[p+p_{0}(1-\beta)\right] E(X-r)^{+}}{Q}+\frac{C\left(L_{i}\right) D}{Q} .
$$

\subsection{Vendor Cost}

The integrated model is planned as follows: the vendor produces $m Q$ units with a finite production rate $P$ at one setup with $P>D$, but shipment of quantity $Q$ happens to the buyer over $m$ times and continues making the delivery on average $Q / D$ units of time. Fig. 1 depicts the behavior of vendor's inventory pattern. The vendor's average inventory is the difference between the vendor and the buyer accumulated inventories (Chang et al., 2006). Hence, the average inventory for the vendor can be given as follows,

$$
\frac{\left\{m Q\left[\frac{Q}{P}+(m-1) \frac{Q}{D}\right]-\frac{m^{2} Q^{2}}{2 P}-\left\{\frac{Q^{2}}{D}[1+2+\ldots+(m-1)]\right\}\right\}}{(m Q / D)} .
$$


Applying some simplification results the average inventory for the vendor as follows,

$$
\frac{Q}{2}\left[m\left(1-\frac{D}{P}\right)-1+\frac{2 D}{P}\right] \text {. }
$$

Thus, the total expected annual cost function for the vendor includes the setup cost, the inventory holding cost and the crashing cost for the setup cost.

$$
E A C_{V}\left(Q, A_{V}, m\right)=\frac{A_{v} D}{m Q}+\frac{h_{v} Q}{2}\left[m\left(1-\frac{D}{P}\right)-1+\frac{2 D}{P}\right]+\frac{R\left(A_{V j}\right) D}{m Q} .
$$

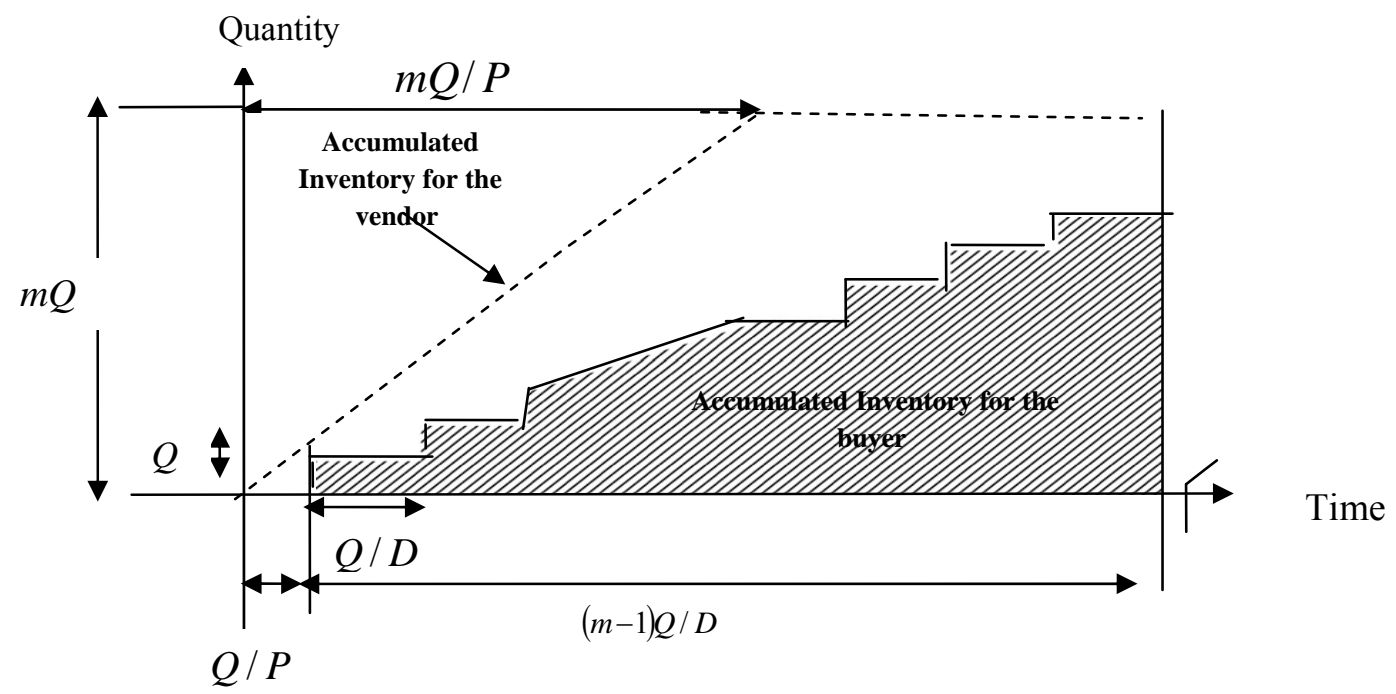

Fig. 1. The vendor's inventory pattern

\subsection{Joint Total Expected Cost}

Our target is to minimize the joint total expected cost (JTEC) per year for the vendor and the buyer i.e.

$\min \operatorname{JTEC}\left(Q, A_{V}, L, m\right)=$ Buyer cost + Vendor cost

$$
\begin{aligned}
& \operatorname{JTEC}\left(Q, A_{V}, L, m\right)=\frac{A_{b} D}{Q}+\frac{h_{b} Q}{2}+h_{b}\left[r-D L+(1-\beta) E(X-r)^{+}\right]+ \\
& \frac{D\left[p+p_{0}(1-\beta)\right] E(X-r)^{+}}{Q}+\frac{C\left(L_{i}\right) D}{Q}+\frac{A_{v} D+R\left(A_{V j}\right) D}{m Q}+\frac{h_{v} Q}{2}\left[m\left(1-\frac{D}{P}\right)-1+\frac{2 D}{P}\right] .
\end{aligned}
$$

Two cases are considered for stochastic lead time demand i.e. complete demand information and partial demand information.

\section{Case 1 Complete demand information}

The lead-time demand is assumed to be known and represented by $X$, which follows a normal distribution with mean $D L$ and standard deviation $\sigma \sqrt{L}$. Therefore, the expected demand shortage at the end of the cycle can be given as $E(X-r)^{+}=\int_{r}^{\infty}(x-r) d F(x)=\sigma \sqrt{L} \psi(k)$, where $\psi(k) \equiv \phi(k)-k[1-\Phi(k)]$, and $\phi, \Phi$ are the standard normal p.d.f. and d.f. Hence, the Eq. (4) is reduced to the following, 


$$
\begin{aligned}
& \operatorname{JTEC}\left(Q, A_{V}, L, m\right)=\frac{A_{b} D}{Q}+\frac{h_{b} Q}{2}+h_{b}[k \sigma \sqrt{L}+(1-\beta) \sigma \sqrt{L} \psi(k)]+\frac{D\left[p+p_{0}(1-\beta)\right] \sigma \sqrt{L} \psi(k)}{Q} \\
& +\frac{C\left(L_{i}\right) D}{Q}+\frac{A_{v} D+R\left(A_{V j}\right) D}{m Q}+\frac{h_{v} Q}{2}\left[m\left(1-\frac{D}{P}\right)-1+\frac{2 D}{P}\right] .
\end{aligned}
$$

In order to find the optimal values of $A_{V}, Q, L$ and $m$, we relax the integer constraint on $m$ to verify the convexity of $\operatorname{JTEC}\left(Q, A_{V}, L, m\right)$ with respect to $A_{V}, Q, L$ and $m$. Therefore, the necessary condition of optimality which are given as follows,

$$
\frac{\partial J T E C\left(Q, A_{V}, L, m\right)}{\partial A_{V}}=0, \frac{\partial J T E C\left(Q, A_{V}, L, m\right)}{\partial Q}=0, \frac{\partial J T E C\left(Q, A_{V}, L, m\right)}{\partial m}=0 \text { and } \frac{\partial J T E C\left(Q, A_{V}, L, m\right)}{\partial L}=0 .
$$

Since the function $\operatorname{JTEC}\left(Q, A_{V}, L, m\right)$ is linear with respect to $A_{V}$, it could be taken as concave as well as convex too. Therefore, treating $A_{V}$ as fixed cost item, the first derivative with respect to the remaining variables yields,

$$
\begin{aligned}
& \frac{\partial J T E C\left(Q, A_{V}, L, m\right)}{\partial Q}=0 \Rightarrow-\frac{A_{b} D}{Q^{2}}+\frac{h_{b}}{2}-\frac{D\left[p+p_{0}(1-\beta)\right] \sigma \sqrt{L} \psi(k)}{Q^{2}}-\frac{C(L) D}{Q^{2}} \\
& -\frac{A_{v} D}{m Q^{2}}+\frac{h_{v}}{2}\left[m\left(1-\frac{D}{P}\right)-1+\frac{2 D}{P}\right]-\frac{R\left(A_{V j}\right) D}{m Q^{2}}=0 \Rightarrow \\
& Q=\left[\frac{2\left\{A_{b} D+\frac{A_{v} D}{m}+D\left[p+p_{0}(1-\beta)\right] \sigma \sqrt{L} \psi(k)+D C\left(L_{i}\right)+\frac{R\left(A_{V j}\right) D}{m}\right\}}{h_{b}+h_{v}\left\{m\left(1-\frac{D}{P}\right)-1+\frac{2 D}{P}\right\}}\right], \\
& \frac{\partial J T E C(Q, k, L, m)}{\partial m}=0 \Rightarrow-\frac{A_{v} D+R\left(A_{V j}\right) D}{m^{2} Q}+\frac{h_{v} Q}{2}\left(1-\frac{D}{P}\right)=0, \\
& \frac{\partial J T E C\left(Q, A_{V}, L, m\right)}{\partial L}=0 \Rightarrow \frac{1}{2} h_{b} \sigma L^{-1 / 2}[k+(1-\beta) \psi(k)]+\frac{D\left[p+p_{0}(1-\beta)\right] \sigma L^{1 / 2} \psi(k)}{2 Q}-\frac{D c_{i}}{Q} .
\end{aligned}
$$

The sufficient condition for the minimum of $\operatorname{JTEC}\left(Q, A_{V}, L, m\right)$ with respect to $L$ is that the second derivate of the objective function with respect to $L$ becomes negative, i.e. $\frac{\partial^{2} \operatorname{JTEC}\left(Q, A_{V}, L, m\right)}{\partial L^{2}}<0$, since $\frac{\partial^{2} \operatorname{JTEC}\left(Q, A_{V}, L, m\right)}{\partial L^{2}}=-\frac{1}{4} h_{b} \sigma L^{-3 / 2}[k+(1-\beta) \psi(k)]-\frac{D\left[p+p_{0}(1-\beta)\right] \sigma L^{-3 / 2} \psi(k)}{4 Q}<0$

Hence, $\operatorname{JTEC}\left(Q, A_{V}, L, m\right)$ is a concave function of $L \in\left(L_{i}, L_{i-1}\right)$. Moreover, for fixed $A_{V}$ and $L \in\left(L_{i,} L_{i-1}\right), \operatorname{JTEC}\left(Q, A_{V}, L, m\right)$ is a convex function of $Q$ and $m$ (See Appendix A for details).

Also, for fixed $Q, A_{V}$ and $m$, the minimum total expected cost occurs at the end points of the interval $L \in\left(L_{i}, L_{i-1}\right)$. Since, $m$ is a discrete variable, thus, the necessary conditions for $m$ to be the optimal are as follows. 
$\operatorname{JTEC}\left(m^{*}\right) \leq \operatorname{JTEC}\left(m^{*}+1\right)$ and $\operatorname{JTEC}\left(m^{*}\right) \leq \operatorname{JTEC}\left(m^{*}-1\right)$, which implies the optimal number of shipment $\left(m^{*}\right)$ must satisfy the following condition (See Appendix B for details),

$$
m^{*}\left(m^{*}-1\right) \leq \frac{\left(A_{v} D+R\left(A_{v j}\right) D\right)\left(h_{b}-h_{v}+h_{v} \frac{2 D}{P}\right)}{h_{v}\left(1-\frac{D}{P}\right)\left(A_{b}+D\left[p+p_{0}(1-\beta)\right] \sigma \sqrt{L} \psi(k)+D C\left(L_{i}\right)\right)} \leq m^{*}\left(m^{*}+1\right) .
$$

To determine the optimal value of the decision variables $Q, A_{V}, L$ and $m$, an iterative procedure is proposed by considering $m$ as fixed, which is a discrete variable.

\section{Iterative Procedure 1}

Step 1: Set $m=1$

Step 2: For each $i=0,1,2, \ldots n$, execute (a)-(d)

(a) For each $j=0,1,2, \ldots m$, execute (b)-(d)

(b) Put $L_{i}$ and $A_{V j}$ in Eq. (6) and calculate the corresponding value of $Q_{i j}$

(c) Calculate the value of JTEC $\left(Q_{i j}, A_{V j}, L_{i}, m\right)$ from the Eq. (5)

(d) Obtain the minimum of $\operatorname{JTEC}\left(Q_{i j}, A_{V j}, L_{i}, m\right)$ for particular and go to step 3

Step 3: Set $m^{\prime}=m+1$ and go to step 2 to get $\operatorname{JTEC}\left(Q_{\left(m^{\prime}\right)}^{*}, A_{V\left(m^{\prime}\right)}^{*}, L_{\left(m^{\prime}\right)}^{*}, m^{\prime}\right)$ and go to step 4

Step 4: If JTEC $\left(Q_{\left(m^{\prime}\right)}^{*}, A_{V\left(m^{\prime}\right)}^{*}, L_{\left(m^{\prime}\right)}^{*}, m^{\prime}\right) \leq \operatorname{JTEC}\left(Q_{(m)}^{*}, A_{V(m)}^{*}, L_{(m)}^{*}, m\right)$, then, set $m=m^{\prime}$ and go to step 3. Otherwise, go to step 5

Step 5: Set $\left(Q^{*}, A_{V}^{*}, L^{*}, m^{*}\right)=\left(Q_{(m)}^{*}, A_{V(m)}^{*}, L_{(m)}^{*}, m\right)$, then $\left(Q^{*}, A_{V}^{*}, L^{*}, m^{*}\right)$ is the optimal solution

\section{Case 2: Partial demand information}

In this case, we relaxe the assumption that the demand during the lead time is known and follows normal distribution. Instead, we consider the partial demand information for the lead time demand, which has an unknown distribution but known mean $D L$ and standard deviation $\sigma \sqrt{L}$. We use the inequality stated by Gallego and Moon (1993) which considers minimax distribution free approach i.e. For any arbitrary distribution $F$ we have,

$$
E(X-r)^{+} \leq \frac{1}{2}\left\{\sqrt{\sigma^{2} L+(r-D L)^{2}}-(r-D L)\right\} .
$$

Therefore, the Eq. (4) is reduced to the following,

$$
\begin{aligned}
& \operatorname{JTEC}^{s}\left(Q, A_{v}, k, L, m\right)=\frac{A_{b} D}{Q}+\frac{h_{b} Q}{2}+h_{b}\left[k \sigma \sqrt{L}+\frac{(1-\beta) \sigma \sqrt{L}\left(\sqrt{1+k^{2}}-k\right)}{2}\right]+ \\
& \frac{D\left[p+p_{0}(1-\beta)\right] \sigma \sqrt{L}\left(\sqrt{1+k^{2}}-k\right)}{2 Q}+\frac{C\left(L_{i}\right) D}{Q}+\frac{A_{v} D}{m Q}+\frac{h_{v} Q}{2}\left[m\left(1-\frac{D}{P}\right)-1+\frac{2 D}{P}\right]+\frac{R\left(A_{V j}\right) D}{m Q},
\end{aligned}
$$


where $\operatorname{JTEC}^{s}\left(Q, A_{V}, k, L, m\right)$ is the least upper bound of $\operatorname{JTEC}\left(Q, A_{V}, k, L, m\right)$. In this case, it is difficult to obtain the value of the safety factor depending on the service level. Therefore, we consider safety factor as one of the decision variable. Similarly, as stated in the previous section, it can be shown that $J_{T E C}\left(Q, A_{V}, k, L, m\right)$ is a concave function of $L \in\left(L_{i} L_{i-1}\right)$ for fixed $\left(Q, A_{V}, k, m\right)$ (See Appendix $\mathrm{C}$ for more details). By fixing $A_{V}$ and $L \in\left(L_{i} L_{i-1}\right)$, one can check that $\operatorname{JTEC}^{s}\left(Q, A_{V}, k, L, m\right)$ is a convex function in $Q, k$ and $m$ (Appendix D). By relaxing the integer requirement and using the necessary conditions of optimality i.e. equating the first derivatives of function $\operatorname{JTEC}^{s}\left(Q, A_{V}, k, L, m\right)$ with respect to $Q, k$ and $m$ to zero we have,

$$
\begin{aligned}
& \frac{\partial \operatorname{JTEC}^{s}\left(Q, A_{V}, k, L, m\right)}{\partial Q}=0 \Rightarrow-\frac{A_{b} D}{Q^{2}}+\frac{h_{b}}{2}-\frac{D\left[p+p_{0}(1-\beta)\right] \sigma \sqrt{L}\left(\sqrt{1+k^{2}}-k\right)}{2 Q^{2}}-\frac{C\left(L_{i}\right) D}{Q^{2}}-\frac{A_{v} D}{m Q^{2}} \\
& -\frac{C\left(L_{i}\right) D}{Q^{2}}-\frac{A_{v} D}{m Q^{2}}+\frac{h_{v}}{2}\left[m\left(1-\frac{D}{P}\right)-1+\frac{2 D}{P}\right]-\frac{R\left(A_{V j}\right) D}{m Q^{2}}=0 . \\
& \Rightarrow Q=\left[\frac{2\left\{A_{b} D+\frac{A_{v} D}{m}+D\left[p+p_{0}(1-\beta)\right] \frac{\sigma \sqrt{L}\left(\sqrt{1+k^{2}}-k\right)}{2}+D C\left(L_{i}\right)+\frac{R\left(A_{V j}\right) D}{m}\right\}}{h_{b}+h_{v}\left\{m\left(1-\frac{D}{P}\right)-1+\frac{2 D}{P}\right\}}\right]^{\frac{1}{2}},
\end{aligned}
$$

$$
\begin{aligned}
& \frac{\partial \operatorname{JTEC}^{s}\left(Q, A_{V}, k, L, m\right)}{\partial k}=0 \Rightarrow h_{b} \sigma \sqrt{L}+\left[\frac{h_{b} \sigma \sqrt{L}(1-\beta)}{2}+\frac{D\left[p+p_{0}(1-\beta)\right] \sigma \sqrt{L}}{2 Q}\right]\left(\frac{k}{\sqrt{1+k^{2}}}-1\right) \\
& \Rightarrow \frac{2 \sqrt{1+k^{2}}}{\sqrt{1+k^{2}-k}}=\frac{D\left[p+p_{0}(1-\beta)\right]}{h_{b} Q}+(1-\beta),
\end{aligned}
$$$$
\frac{\partial J T E C^{s}\left(Q, A_{V}, k, L, m\right)}{\partial m}=-\frac{A_{v} D+R\left(A_{V j}\right) D}{m^{2} Q}+\frac{h_{v} Q}{2}\left(1-\frac{D}{P}\right) .
$$

Since $m$ is a discrete variable, it must satisfy the condition of optimality given as:

$$
m^{*}\left(m^{*}-1\right) \leq \frac{\left(A_{v} D+R\left(A_{v j}\right) D\right)\left(h_{b}-h_{v}+h_{v} \frac{2 D}{P}\right)}{h_{v}\left(1-\frac{D}{P}\right)\left(A_{b}+D\left[p+p_{0}(1-\beta)\right]\left(\frac{\sigma \sqrt{L}\left(\sqrt{1+k^{2}}-k\right)}{2}\right)+D C\left(L_{i}\right)\right)} \leq m^{*}\left(m^{*}+1\right) .
$$

An iterative procedure is required to find the optimal value of the decision variables $Q, A_{V}, k, L$ and $m$ for distribution free model.

\section{Iterative Procedure 2}

Step 1: Set $m=1$ 
Step 2: For each $i=0,1,2, \ldots n$, execute (a)-(g)

(a) $\quad$ For each $j=0,1,2, \ldots m$, execute (b)-(g)

(b) Initially, take the value of safety factor as $k_{i j}=0$

(c) By substituting the value of $k_{i j}, L_{i}$ and $A_{V j}$ into Eq. (11), calculate $Q_{i j}$

(d) Substitute the value of $Q_{i j}$ into Eq. (12) and evaluate $k_{i j}$

(e) Repeat (c) and (d) until no change occurs in the values of $Q_{i j}$ and $k_{i j}$

(f) Calculate the value of $\operatorname{JTEC}^{s}\left(Q_{i j}, A_{V j}, k_{i j}, L_{i}, m\right)$ from the Eq. (10)

(g) Obtain the minimum of $\operatorname{JTEC}^{s}\left(Q_{i j}, A_{V j}, k_{i j}, L_{i}, m\right)$ for particular $i$ and $j$ and go to step 3

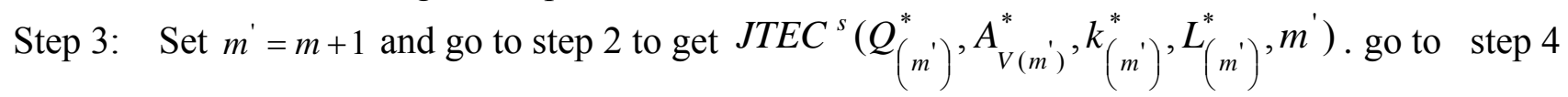

Step 4: If $\operatorname{JTEC}^{s}\left(Q_{\left(m^{\prime}\right)}^{*}, A_{V\left(m^{\prime}\right)}^{*}, k_{\left(m^{\prime}\right)}^{*}, L_{\left(m^{\prime}\right)}^{*}, m^{\prime}\right) \leq J T E C^{s}\left(Q_{(m)}^{*}, A_{V(m)}^{*}, k_{(m)}^{*}, L_{(m)}^{*}, m\right)$, then, set $m=m^{\prime}$ and go to step 3, Otherwise, go to step 5

Step 5: $\quad$ Set $\left(Q^{*}, A_{V}^{*}, k^{*}, L^{*}, m^{*}\right)=\left(Q_{(m)}^{*}, A_{V(m)}^{*}, k_{(m)}^{*}, L_{(m)}^{*}, m\right)$, then $\left(Q^{*}, A_{V}^{*}, k^{*}, L^{*}, m^{*}\right)$ is the optimal solution.

\section{Numerical examples}

\subsection{Example 1}

In order to illustrate the model, an inventory system with the following data are considered: $\mathrm{D}=600$ units/year, $A_{b}=\$ 200 /$ order, $A_{v}=\$ 300 /$ setup, $h_{b}=\$ 20 /$ unit/year, $h_{v}=\$ 4 /$ unit $/$ year, $p=\$ 50 /$ unit, $p_{0}=\$ 150 /$ unit, $\sigma=7$ units/week, $P=3200$ units/year. The lead-time and setup cost have three components shown in Table 1 and Table 2.

\section{Table 1}

Lead-time data

\begin{tabular}{lcccc}
\hline Lead time component, $i$ & $\begin{array}{l}\text { Normal duration, } b_{i} \\
\text { (days) }\end{array}$ & $\begin{array}{l}\text { Minimum duration, } a_{i} \\
\text { (days) }\end{array}$ & $\begin{array}{l}\text { Unit Crashing cost per } \\
\text { day, } c_{i}\end{array}$ \\
\hline 1 & 20 & 6 & 0.4 \\
2 & 20 & 6 & 1.2 \\
3 & 16 & 9 & 5.0 \\
\hline
\end{tabular}

\section{Table 2}

Setup cost data

\begin{tabular}{lccc}
\hline $\begin{array}{l}\text { Setup cost component, } \\
i\end{array}$ & Normal cost, $e_{i}$ & $\begin{array}{l}\text { Minimum cost, } \\
d_{i}\end{array}$ & $\begin{array}{l}\text { Total crashing cost as reduced to } \\
\text { minimum cost, } f_{i}\end{array}$ \\
\hline 1 & 130 & 40 & 56 \\
2 & 80 & 20 & 168 \\
3 & 90 & 40 & 350 \\
\hline
\end{tabular}


First, we considered that the shortages are partially backlogged i.e. $\beta=0.5$ and fixed service level is 0.8 that is, $k=0.84$ and $\psi(k)=0.1120$ by checking the table given by Silver and Peterson (1985). The optimal solutions for different decision variables i.e. $Q, A_{V}, L$ and $m$ when we do not consider the crashing of lead time and setup cost and the lead time demand follows normal distribution displayed in Table 3.

Table 3

Optimal solution for $\beta=0.5$ without crashing for normally distributed demand

\begin{tabular}{llllllll}
\hline$i$ & $L$ (weeks) & $A_{V}$ & $m^{*}$ & $Q^{*}$ & JTEC(.) & Vendor cost & Buyer cost \\
\hline 0 & 8 & 300 & 1 & 198.44 & 6231.20 & 936.20 & 5295.00 \\
\hline
\end{tabular}

We have also obtained the optimal values of $Q, A_{V}, L$ and $m$ by considering the crashing of lead time and setup cost and the results are presented in Table 4.

Table 4

Optimal solutions for $\beta=0.5$ with crashing of lead time and setup $\operatorname{cost} A_{V}$ for normally distributed demand

\begin{tabular}{llllllll}
\hline$i$ & $L$ (weeks) & $A_{V}$ & $m^{*}$ & $Q^{*}$ & $J T E C()$. & Vendor cost & Buyer cost \\
\hline \multirow{3}{*}{0} & 8 & 210 & 1 & 197.37 & 6173.66 & 873.33 & 5300.33 \\
& 8 & 150 & 1 & 200.46 & 6346.81 & 1061.37 & 5285.43 \\
& 8 & 100 & 2 & 206.15 & 6731.48 & 1469.85 & 5261.63 \\
\hline \multirow{3}{*}{1} & 6 & 210 & 1 & 185.79 & 5553.94 & 841.30 & 4712.64 \\
& 6 & 150 & 1 & 188.16 & 5734.03 & 1029.76 & 4704.27 \\
& 6 & 100 & 2 & 192.54 & 6131.05 & 1440.16 & 4690.89 \\
\hline \multirow{3}{*}{2} & 4 & 210 & 1 & 175.27 & 4915.43 & 819.30 & 4096.13 \\
& 4 & 150 & 2 & 176.74 & 5101.21 & 1007.77 & 4093.44 \\
& 4 & 100 & 2 & 179.48 & 5508.48 & 1419.30 & 4089.18 \\
\hline \multirow{3}{*}{3} & 3 & 210 & 2 & 174.64 & 4658.05 & 807.89 & 3850.16 \\
& 3 & 150 & 2 & 175.57 & 4845.91 & 996.44 & 3849.47 \\
& 3 & 100 & 3 & 177.31 & 5256.98 & 1408.52 & 3848.46 \\
\hline
\end{tabular}

\subsection{Example 2}

We assume that the lead-time demand distribution is unknown with first two known finite moments for the same data given in example 1. The optimal solutions for different decision variables have been determined with/without the crashing of setup cost and the results are summarized in Table 5 and Table 6.

\section{Table 5}

Optimal solution for $\beta=0.5$ without crashing for unknown demand

\begin{tabular}{lllllllll}
\hline$i$ & $L$ (weeks) & $A_{V}$ & $k^{*}$ & $m^{*}$ & $Q^{*}$ & $J_{T E C}{ }^{s}()$. & Vendor cost & Buyer cost \\
\hline 0 & 8 & 300 & 2.10 & 1 & 186.84 & 6791.94 & 887.10 & 5904.84 \\
\hline
\end{tabular}


Table 6

Optimal solutions for $\beta=0.5$ with crashing of lead time and setup cost $A_{V}$ for unknown demand

\begin{tabular}{lllllllll}
\hline$i$ & $L$ (weeks) & $A_{V}$ & $k^{*}$ & $m^{*}$ & $Q^{*}$ & $J^{*} C^{s}()$. & Vendor cost & Buyer cost \\
\hline 0 & 8 & 210 & 2.10 & 1 & 186.06 & 6731.04 & 824.19 & 5906.85 \\
& 8 & 150 & 2.09 & 2 & 188.31 & 6913.78 & 1012.55 & 5901.23 \\
& 8 & 100 & 2.06 & 2 & 192.51 & 7315.47 & 1423.27 & 5892.21 \\
\hline 1 & 6 & 210 & 2.16 & 1 & 176.88 & 6001.72 & 817.13 & 5184.58 \\
& 6 & 150 & 2.15 & 2 & 178.50 & 6187.51 & 1005.47 & 5182.05 \\
& 6 & 100 & 2.13 & 2 & 181.52 & 6594.80 & 1416.74 & 5178.07 \\
\hline 2 & 4 & 210 & 2.22 & 2 & 169.30 & 5263.97 & 813.50 & 4450.47 \\
& 4 & 150 & 2.21 & 2 & 170.22 & 5452.02 & 1001.97 & 4450.05 \\
& 4 & 100 & 2.20 & 3 & 171.96 & 5863.44 & 1413.96 & 4449.48 \\
\hline 3 & 3 & 210 & 2.21 & 2 & 170.84 & 4963.54 & 807.41 & 4156.12 \\
& 3 & 150 & 2.20 & 2 & 171.40 & 5152.31 & 996.09 & 4156.22 \\
& 3 & 100 & 2.20 & 3 & 172.46 & 5565.07 & 1408.58 & 4156.49 \\
\hline
\end{tabular}

4.3 Sensitivity on $\beta$ (backorder ratio)

We have solved diffenent cases for known and unknown lead time demand with $\beta=(0,0.2,0.5,0.7,1)$.

Table 7

Summary of the optimal results for normally distributed demand

\begin{tabular}{|c|c|c|c|c|c|c|c|c|c|c|c|}
\hline$\beta$ & Decision & $L^{*}$ & $A_{V}^{*}$ & $Q^{*}$ & $m^{*}$ & $\begin{array}{l}\text { Vendor } \\
\text { cost }\end{array}$ & $\begin{array}{l}\text { Buyer } \\
\text { cost }\end{array}$ & JTEC(.) & $\begin{array}{l}\text { Vendor } \\
\text { Savins }\end{array}$ & $\begin{array}{l}\text { Buyer } \\
\text { Savins }\end{array}$ & $\begin{array}{l}\text { Total } \\
\text { Savings } \\
\end{array}$ \\
\hline \multirow{2}{*}{0} & \multirow{2}{*}{$\begin{array}{l}\text { Without } \\
\text { crashing } \\
\text { With } \\
\text { Crashing }\end{array}$} & 8 & 300 & 234.43 & 1 & 928.53 & 6416.61 & 7345.13 & \multirow{2}{*}{15.40} & \multirow{2}{*}{31.32} & \multirow{2}{*}{29.31} \\
\hline & & 3 & 210 & 196.06 & 1 & 785.49 & 4406.84 & 5192.33 & & & \\
\hline \multirow{2}{*}{0.2} & \multirow{2}{*}{$\begin{array}{l}\text { Without } \\
\text { crashing } \\
\text { With } \\
\text { Crashing }\end{array}$} & 8 & 300 & 220.89 & 1 & 931.69 & 5992.27 & 6923.96 & \multirow[t]{2}{*}{14.76} & \multirow[t]{2}{*}{30.02} & \multirow[t]{2}{*}{27.97} \\
\hline & & 3 & 210 & 187.83 & 2 & 794.10 & 4192.81 & 4986.91 & & & \\
\hline \multirow{2}{*}{0.5} & \multirow{2}{*}{$\begin{array}{l}\text { Without } \\
\text { crashing } \\
\text { With } \\
\text { Crashing }\end{array}$} & 8 & 300 & 198.44 & 1 & 936.20 & 5295.00 & 6231.20 & \multirow{2}{*}{13.71} & \multirow{2}{*}{27.29} & \multirow{2}{*}{25.25} \\
\hline & & 3 & 210 & 174.64 & 2 & 807.89 & 3850.16 & 4658.05 & & & \\
\hline \multirow{2}{*}{0.7} & $\begin{array}{l}\text { Without } \\
\text { crashing }\end{array}$ & 8 & 300 & 181.55 & 1 & 939.11 & 4775.86 & 5714.97 & \multirow[t]{2}{*}{12.91} & \multirow[t]{2}{*}{24.53} & \multirow[t]{2}{*}{22.62} \\
\hline & $\begin{array}{l}\text { With } \\
\text { crashing }\end{array}$ & 3 & 210 & 165.16 & 2 & 817.83 & 3604.14 & 4421.98 & & & \\
\hline \multirow{2}{*}{1} & $\begin{array}{l}\text { Without } \\
\text { crashing }\end{array}$ & 8 & 300 & 151.72 & 2 & 943.86 & 3871.84 & 4815.70 & \multirow{2}{*}{11.60} & \multirow{2}{*}{17.33} & \multirow{2}{*}{16.21} \\
\hline & $\begin{array}{l}\text { With } \\
\text { Crashing }\end{array}$ & 3 & 300 & 149.62 & 2 & 834.37 & 3200.70 & 4035.07 & & & \\
\hline
\end{tabular}

Note: Savings $\%=\left\{(\right.$ JTEQ(without crashing) $-J T E Q($ with crashing $) / J T E Q($ without crashing $)\} \times 100 \%, L^{*}:$ in week 
The optimal results have been presented in Table 7 with crashing of setup cost and lead time compared with the outcomes obtained for the same problem without crashing where the lead time demand follows normal distribution. It can be seen that the JTEC (.) has minimum value when $\beta=1$ (pure backorder case) and maximum value when $\beta=0$ (pure lost sales case). Moreover, Table 8 shows the outcomes given for both situations i.e. with and without crashing where lead time demand has unknown distribution.

\section{Table 8}

Summary of the optimal results for Unknown demand

\begin{tabular}{|c|c|c|c|c|c|c|c|c|c|c|c|c|}
\hline$\beta$ & Decision & $L^{*}$ & $A_{V}^{*}$ & $k^{\prime}$ & $Q^{*}$ & $m^{*}$ & $\begin{array}{l}\text { Vendor } \\
\text { cost }\end{array}$ & $\begin{array}{l}\text { Buyer } \\
\text { cost }\end{array}$ & $J T E C^{s}()$. & $\begin{array}{l}\text { Vendor } \\
\text { Savings } \\
(\%)\end{array}$ & $\begin{array}{l}\text { Buyer } \\
\text { Saving } \\
\text { s (\%) }\end{array}$ & $\begin{array}{l}\text { Total } \\
\text { Savings } \\
(\%)\end{array}$ \\
\hline \multirow[b]{2}{*}{0} & $\begin{array}{l}\text { Without } \\
\text { crashing }\end{array}$ & 8 & 300 & 2.59 & 208.07 & 1 & 863.02 & 6727.81 & 7590.83 & \multirow[b]{2}{*}{8.18} & \multirow[b]{2}{*}{32.06} & \multirow[b]{2}{*}{29.35} \\
\hline & $\begin{array}{l}\text { With } \\
\text { Crashing }\end{array}$ & 3 & 210 & 2.78 & 182.78 & 2 & 792.40 & 4570.59 & 5362.99 & & & \\
\hline \multirow[b]{2}{*}{0.2} & $\begin{array}{l}\text { Without } \\
\text { crashing }\end{array}$ & 8 & 300 & 2.41 & 200.43 & 1 & 868.32 & 6425.92 & 7297.24 & \multirow[b]{2}{*}{8.10} & \multirow[b]{2}{*}{31.24} & \multirow[b]{2}{*}{28.52} \\
\hline & $\begin{array}{l}\text { With } \\
\text { Crashing }\end{array}$ & 3 & 210 & 2.57 & 178.46 & 2 & 797.78 & 4417.90 & 5215.68 & & & \\
\hline \multirow[b]{2}{*}{0.5} & $\begin{array}{l}\text { Without } \\
\text { crashing }\end{array}$ & 8 & 300 & 2.10 & 186.84 & 1 & 878.10 & 5904.84 & 6791.94 & \multirow[b]{2}{*}{8.04} & \multirow[b]{2}{*}{29.62} & \multirow[b]{2}{*}{26.92} \\
\hline & $\begin{array}{l}\text { With } \\
\text { Crashing }\end{array}$ & 3 & 210 & 2.21 & 170.84 & 2 & 807.41 & 4156.12 & 4963.54 & & & \\
\hline \multirow[b]{2}{*}{0.7} & $\begin{array}{l}\text { Without } \\
\text { crashing }\end{array}$ & 8 & 300 & 1.84 & 175.43 & 1 & 885.49 & 5491.23 & 6392.72 & \multirow[b]{2}{*}{7.92} & \multirow[b]{2}{*}{28.07} & \multirow[b]{2}{*}{25.46} \\
\hline & $\begin{array}{l}\text { Without } \\
\text { crashing }\end{array}$ & 3 & 210 & 1.92 & 164.52 & 2 & 815.60 & 3949.70 & 4765.29 & & & \\
\hline \multirow[b]{2}{*}{1} & $\begin{array}{l}\text { Without } \\
\text { crashing }\end{array}$ & 8 & 300 & 1.33 & 150.88 & 2 & 905.20 & 4691.79 & 5632.92 & \multirow[b]{2}{*}{7.87} & \multirow[b]{2}{*}{24.28} & \multirow[b]{2}{*}{22.12} \\
\hline & $\begin{array}{l}\text { With } \\
\text { Crashing }\end{array}$ & 3 & 210 & 1.33 & 150.79 & 3 & 834.58 & 3552.61 & 4387.19 & & & \\
\hline
\end{tabular}

Note: Savings \% $=\{(J T E C$ (without crashing) $-J T E C$ (with crashing $) / J T E C$ (without crashing $)\} \times 100 \%$, $L^{*}$ : in weeks

\section{Observations}

It has been observed from Tables 7 and 8 , which represents $\beta=(0,0.2,0.5,0.7,1)$ including the case of lost sale $(\beta=0)$, partially backlogged demand $(\beta=0.5)$ and fully backlogged $(\beta=1)$ that the crashing of the lead time on the buyer's side and reduction of the setup cost on the vendor's part brings significant savings for the joint total expected cost for the supply chain. The expected cost for both members are reduced with the implementation of JIT technology whereas the buyer generates more benefits for vendor. It has also been noted that the joint total expected cost decreases as the backorder ratio increases, since the buyer can fetch a large number of backorders by reducing the lead-time. It is appealing to find that crashing of the lead time and setup cost brings significant savings (approx 25-29\%) represented in Table 7 and Table 8. Furthermore, we found that the number 
of shipments $(m)$ increases with the reduction of the lead time i.e. the buyer would like to place and order frequently instead of keeping large amount of safety stocks.

\section{Conclusion}

The present study highlights the benefits achieved by the coordination of vendor-buyer where the vendor's purpose is to reduce the setup cost and the buyer's intention is to reduce the lead time. Thus, the joint total expected cost also includes the setup crashing cost and lead-time crashing cost. This collaboration helps to reduce the total cost of the integrated vendor-buyer stochastic inventory system. Moreover, the findings clearly show that there are significant savings by crashing the components of the vendor's setup cost and buyer's lead time.

\section{Appendix A}

To prove the convexity of $\operatorname{JTEC}\left(Q, A_{V}, L, m\right)$ with respect to $Q$ and $m$ for the case (i) Complete demand information. We have shown that the Hessian Matrix of $\operatorname{JTEC}(Q, m)$ is positive definite.

$H=\left[\begin{array}{ll}\frac{\partial^{2} J T E C(.)}{\partial Q^{2}} & \frac{\partial^{2} J T E C(.)}{\partial Q \partial m} \\ \frac{\partial^{2} J T E C(.)}{\partial m \partial Q} & \frac{\partial^{2} J T E C(.)}{\partial Q^{2}}\end{array}\right]$,

where $\operatorname{JTEC}()=.\operatorname{JTEC}\left(Q, A_{V}, k, L, m\right)$. We have ,

$\frac{\partial^{2} J \operatorname{JTEC}(.)}{\partial Q^{2}}=\frac{2 A_{b} D}{Q^{3}}+\frac{2 D\left[p+p_{0}(1-\beta)\right] \sigma \sqrt{L} \psi(k)}{Q^{3}}+\frac{2 C\left(L_{i}\right) D}{Q^{3}}+\frac{2 A_{v} D+2 R\left(A_{v j}\right) D}{m Q^{3}}>0$,

$\frac{\partial^{2} \operatorname{JTEC}(Q, k, L, m)}{\partial m^{2}}=\frac{2 A_{v} D+2 R\left(A_{V j}\right) D}{m^{3} Q}$,

$\frac{\partial^{2} \operatorname{JTEC}(.)}{\partial Q \partial m}=\frac{\partial^{2} \operatorname{JTEC}(.)}{\partial m \partial Q}=\left(\frac{A_{v} D+R\left(A_{V j}\right) D}{m^{2} Q^{2}}\right)+\frac{h_{v}}{2}\left(1-\frac{D}{P}\right)$.

Now, it can be easily seen that the first principal minor determinant of $\mathrm{H}$ is positive as

$\left|H_{11}\right|==\frac{2 A_{b} D}{Q^{3}}+\frac{2 D\left[p+p_{0}(1-\beta)\right] \sigma \sqrt{L} \psi(k)}{Q^{3}}+\frac{2 C\left(L_{i}\right) D}{Q^{3}}+\frac{2 A_{v} D}{m Q^{3}}+\frac{2 R\left(A_{V j}\right) D}{m Q^{3}}>0$.

The second principal minor determinant of $H$ can be calculated by substituting the derivatives from above and searched out to be

$\left|H_{22}\right|=\frac{\partial^{2} \operatorname{JTEC}(.)}{\partial Q^{2}} \times \frac{\partial^{2} \operatorname{JTEC}(.)}{\partial m^{2}}-\left(\frac{\partial^{2} \operatorname{JTEC}(.)}{\partial Q \partial m}\right)^{2}$ 
$=\left(\frac{2 A_{b} D}{Q^{3}}+\frac{2 D\left[p+p_{0}(1-\beta)\right] \sigma \sqrt{L} \psi(k)}{Q^{3}}+\frac{2 C\left(L_{i}\right) D}{Q^{3}}\right) \times\left(\frac{2 A_{v} D+2 R\left(A_{v j}\right) D}{m^{3} Q}\right)+$

$\frac{3\left(A_{v} D+R\left(A_{V j}\right) D\right)^{2}}{m^{4} Q^{4}}-2 \frac{h_{v}}{2}\left(1-\frac{D}{P}\right)\left(\frac{A_{v} D+R\left(A_{V j}\right) D}{m^{2} Q^{2}}\right)-\left(\frac{h_{v}}{2}\right)^{2}\left(1-\frac{D}{P}\right)^{2}$

Since $P>D \Rightarrow \frac{D}{P}<1 \Rightarrow\left(1-\frac{D}{P}\right)>0$, and

$\left\{\frac{3\left(A_{v} D+R\left(A_{V j}\right) D\right)^{2}}{m^{4} Q^{4}}-2 \frac{h_{v}}{2}\left(1-\frac{D}{P}\right)\left(\frac{A_{v} D+R\left(A_{V j}\right) D}{m^{2} Q^{2}}\right)-\left(\frac{h_{v}}{2}\right)^{2}\left(1-\frac{D}{P}\right)^{2}\right\}>0 \Rightarrow\left|H_{22}\right|>0$

This completes the proof.

\section{Appendix B}

To prove the optimal condition for $(m)$, we considered a particular value of $L$, then using the Eq. (6) into the Eq. (5) of $\operatorname{JTEC}\left(Q, A_{V}, L, m\right)$ and ignoring the terms which are independent of $m$ provides

$J \operatorname{JTE} C_{1}(m)=\operatorname{JTEC}\left(Q^{*}, A_{V}^{*}, L, m\right)=\left[2 D T(m)\left\{A_{b}+\left[p+p_{0}(1-\beta)\right] \sigma \sqrt{L} \psi(k)+C\left(L_{i}\right)+\frac{A}{m}\right\}\right]^{1 / 2}$

where $T(m)=h_{b}+h_{v}\left\{m\left(1-\frac{D}{P}\right)-1+\frac{2 D}{P}\right\}, A=R\left(A_{V j}\right) D+A_{v} D$

Taking square of $\operatorname{JTEC}_{1}(m)$, yields $\operatorname{JTEC}_{2}(m)=\left[2 D T(m)\left\{A_{b}+\left[p+p_{0}(1-\beta)\right] \sigma \sqrt{L} \psi(k)+C\left(L_{i}\right)+\frac{A}{m}\right\}\right]$.

As $m$ is a positive integer, therefore, the optimal value $m^{*}$ is obtained when

$\operatorname{JTEC}_{2}\left(m^{*}\right) \leq \operatorname{JTEC}_{2}\left(m^{*}+1\right)$,

and

$\operatorname{JTEC}_{2}\left(m^{*}\right) \leq \operatorname{JTEC}_{2}\left(m^{*}-1\right)$.

From (B.1) and (B.2), the optimal value of $(m)$ must satisfy

$m^{*}\left(m^{*}-1\right) \leq \frac{\left(A_{v} D+R\left(A_{V j}\right) D\right)\left(h_{b}-h_{v}+h_{v} \frac{2 D}{P}\right)}{h_{v}\left(1-\frac{D}{P}\right)\left(A_{b}+D\left[p+p_{0}(1-\beta)\right] \sigma \sqrt{L} \psi(k)+D C\left(L_{i}\right)\right)} \leq m^{*}\left(m^{*}+1\right)$.

This completes the proof.

\section{Appendix C}

To show $\operatorname{JTEC}^{s}\left(Q, A_{V}, k, L, m\right)$ is a concave function of $L$ we have,

$\frac{\partial^{2} \operatorname{JTEC}^{s}\left(Q, A_{V}, k, L, m\right)}{\partial L^{2}}=-\frac{1}{4} h_{b} \sigma L^{-3 / 2}\left[k+\frac{(1-\beta)\left(\sqrt{1+k^{2}}-k\right)}{2}\right]-\frac{D\left[p+p_{0}(1-\beta)\right] \sigma L^{-3 / 2} \psi(k)}{8 Q}<0$. 
This completes the proof.

\section{Appendix D}

To prove that $\operatorname{JTEC}^{S}\left(Q, A_{V}, k, L, m\right)$ is a convex function in $Q, k$ and $m$ for fixed $A_{V}$ and $L \in\left(L_{i,} L_{i-1}\right)$ for the case (ii) partial demand information, we need to show that Hessian Matrix of $\operatorname{JTEC}(Q, k, m)$ is positive definite which is given by

$$
H=\left[\begin{array}{lll}
\frac{\partial^{2} J T E C(.)}{\partial Q^{2}} & \frac{\partial^{2} J T E C(.)}{\partial Q \partial k} & \frac{\partial^{2} J T E C(.)}{\partial Q \partial m} \\
\frac{\partial^{2} J T E C(.)}{\partial k \partial Q} & \frac{\partial^{2} J T E C(.)}{\partial k^{2}} & \frac{\partial^{2} J T E C(.)}{\partial k \partial m} \\
\frac{\partial^{2} J T E C(.)}{\partial m \partial Q} & \frac{\partial^{2} J T E C(.)}{\partial m \partial k} & \frac{\partial^{2} J T E C(.)}{\partial m^{2}}
\end{array}\right]
$$

where $\operatorname{JTEC}()=.\operatorname{JTEC}^{s}\left(Q, A_{V}, k, L, m\right)$. We have,

$$
\begin{aligned}
& \frac{\partial^{2} \operatorname{JTEC}(.)}{\partial Q^{2}}=\frac{2 A_{b} D}{Q^{3}}+\frac{D\left[p+p_{0}(1-\beta)\right] \sigma \sqrt{L}\left(\sqrt{1+k^{2}}-k\right)}{Q^{3}}+\frac{2 C\left(L_{i}\right) D}{Q^{3}}+\frac{2 A_{v} D+2 R\left(A_{V j}\right) D}{m Q^{3}}>0 \\
& \frac{\partial^{2} J T E C(.)}{\partial k^{2}}=\left(\frac{h_{b}(1-\beta) \sigma \sqrt{L}}{2}+\frac{D\left[p+p_{0}(1-\beta)\right] \sigma \sqrt{L}}{2 Q}\right) \times\left(\frac{1+k^{2}-k}{2\left(1+k^{2}\right)^{3 / 2}}\right) \\
& \frac{\partial^{2} \operatorname{JTEC}(Q, k, L, m)}{\partial m^{2}}=\frac{\left(2 A_{v} D+2 R\left(A_{V j}\right) D\right)}{m^{3} Q} \\
& \frac{\partial^{2} \operatorname{JTEC}(.)}{\partial Q \partial k}=\frac{\partial^{2} \operatorname{JTEC}(.)}{\partial k \partial Q}=\left(\frac{D\left[p+p_{0}(1-\beta)\right] \sigma \sqrt{L}}{2 Q^{2}}\right) \times\left(\frac{\sqrt{1+k^{2}}-k}{\sqrt{1+k^{2}}}\right) \\
& \frac{\partial^{2} \operatorname{JTEC}(.)}{\partial k \partial m}=\frac{\partial^{2} \operatorname{JTEC}(.)}{\partial m \partial k}=0 \\
& \frac{\partial^{2} \operatorname{JTEC}(.)}{\partial Q \partial m}=\frac{\partial^{2} \operatorname{JTEC}(.)}{\partial m \partial Q}=\left(\frac{A_{v} D+R\left(A_{V j}\right) D}{m^{2} Q^{2}}\right)+\frac{h_{v}}{2}\left(1-\frac{D}{P}\right)
\end{aligned}
$$

Now, it can be easily seen that the first principal minor determinant of $\mathrm{H}$ is positive as

$$
\left|H_{11}\right|=\frac{2 A_{b} D}{Q^{3}}+\frac{D\left[p+p_{0}(1-\beta)\right] \sigma \sqrt{L}\left(\sqrt{1+k^{2}}-k\right)}{Q^{3}}+\frac{2 C\left(L_{i}\right) D}{Q^{3}}+\frac{2 A_{v} D+2 R\left(A_{V j}\right) D}{m Q^{3}}>0 .
$$

The second principal minor determinant of $H$ can be calculated by substituting the derivatives from above and searched out to be

$$
\left|H_{22}\right|=\frac{\partial^{2} \operatorname{JTEC}(.)}{\partial Q^{2}} \times \frac{\partial^{2} \operatorname{JTEC}(.)}{\partial k^{2}}-\left(\frac{\partial^{2} \operatorname{JTEC}(.)}{\partial Q \partial k}\right)^{2}
$$




$$
\begin{aligned}
& \left|H_{22}\right|=\left[\frac{\left(D\left[p+p_{0}(1-\beta)\right] \sigma \sqrt{L}\left(\sqrt{1+k^{2}}-k\right)+2 C(L) D\right)}{Q^{3}}+\frac{2 A_{v} D}{m Q^{3}}+\frac{2 R\left(A_{V j}\right) D}{m Q^{3}}\right] \\
& \left.\times\left(\frac{h_{b}(1-\beta) \sigma \sqrt{L}}{2}\right)\left(\frac{1+k^{2}-k}{2\left(1+k^{2}\right)^{3 / 2}}\right)+\left(\frac{D\left[p+p_{0}(1-\beta)\right] \sigma \sqrt{L}}{2 Q^{4}}\right)^{2} \times\left(\frac{\left(\sqrt{1+k^{2}}-k\right)\left(1+k^{2}-k\right)}{2\left(1+k^{2}\right)^{3 / 2}}-\frac{\left(\sqrt{1+k^{2}}-k\right)^{2}}{1+k^{2}}\right)\right] \\
& =\left[\frac{\left(D\left[p+p_{0}(1-\beta)\right] \sigma \sqrt{L}\left(\sqrt{1+k^{2}}-k\right)+2 C(L) D\right)}{Q^{3}}+\frac{2 A_{v} D}{m Q^{3}}+\frac{2 R\left(A_{V j}\right) D}{m Q^{3}}\right] \times\left(\frac{h_{b}(1-\beta) \sigma \sqrt{L}}{2}\right)\left(\frac{1+k^{2}-k}{2\left(1+k^{2}\right)^{3 / 2}}\right)+ \\
& \left(\frac{D\left[p+p_{0}(1-\beta)\right] \sigma \sqrt{L}}{2 Q^{4}}\right)^{2}\left(\frac{k\left(\sqrt{1+k^{2}}-k\right)\left(\sqrt{1+k^{2}}-1\right)}{2\left(1+k^{2}\right)^{3 / 2}}\right)>0
\end{aligned}
$$

The third principal minor determinant of $H$ can be calculated by substituting the derivatives from above and searched out to be

$$
\begin{aligned}
\left|H_{33}\right|= & \frac{\partial^{2} J T E C(.)}{\partial Q^{2}} \times\left[\begin{array}{ll}
\frac{\partial^{2} J T E C(.)}{\partial k^{2}} & \frac{\partial^{2} J T E C(.)}{\partial k \partial m} \\
\frac{\partial^{2} J T E C(.)}{\partial m \partial k} & \frac{\partial^{2} J T E C(.)}{\partial m^{2}}
\end{array}\right]-\frac{\partial^{2} J T E C(.)}{\partial Q \partial k} \times\left[\begin{array}{cc}
\frac{\partial^{2} J T E C(.)}{\partial k \partial Q} & \frac{\partial^{2} J T E C(.)}{\partial k \partial m} \\
\frac{\partial^{2} J T E C(.)}{\partial m \partial Q} & \left.\frac{\partial^{2} J T E C(.)}{\partial m^{2}}\right]
\end{array}\right] \\
+\frac{\partial^{2} J T E C(.)}{\partial Q \partial m} \times\left[\begin{array}{cc}
\frac{\partial^{2} J T E C(.)}{\partial k \partial Q} & \frac{\partial^{2} J T E C(.)}{\partial k^{2}} \\
\frac{\partial^{2} J T E C(.)}{\partial m \partial Q} & \frac{\partial^{2} J T E C(.)}{\partial m \partial k}
\end{array}\right] & \\
\left|H_{33}\right|= & \left.\frac{D\left[p+p_{0}(1-\beta)\right] \sigma \sqrt{L}}{2 Q^{2}}\right)^{2} \times\left(\frac{k\left(\sqrt{1+k^{2}}-k\right)\left(\sqrt{1+k^{2}}-1\right)}{2\left(1+k^{2}\right)^{3 / 2}}\right)+\left(\frac{2 A_{b} D}{Q^{3}}+\frac{2 C\left(L_{i}\right) D}{Q^{3}}\right) \times \\
& {\left[\left(\frac{h_{b}(1-\beta) \sigma \sqrt{L}}{2}\right) \times\left(\frac{\left(1+k^{2}-k\right)}{\left.2\left(1+k^{2}\right)^{3 / 2}\right)}\right] \times\left[\frac{\left(2 A_{v} D+2 R\left(A_{V j}\right) D\right)}{m^{3} Q}\right]+\right.} \\
& \left(\frac{h_{b}(1-\beta) \sigma \sqrt{L}}{2}+\frac{D\left[p+p_{0}(1-\beta)\right] \sigma \sqrt{L}}{2 Q}\right) \times\left(\frac{1+k^{2}-k}{2\left(1+k^{2}\right)^{3 / 2}}\right) \times \\
& \left\{\frac{3\left(A_{v} D+R\left(A_{V j}\right) D\right)^{2}}{m^{4} Q^{4}}-2 \frac{h_{v}}{2}\left(1-\frac{D}{P}\right)\left(\frac{A_{v} D+R\left(A_{V j}\right) D}{m^{2} Q^{2}}\right)-\left(\frac{h_{v}}{2}\right)^{2}\left(1-\frac{D}{P}\right)^{2}\right\}>0
\end{aligned}
$$

This completes the proof.

\section{Acknowledgement}

The authors are thankful to the anonymous referees for their valuable suggestions and comments, which have helped in improving the present investigation. The first author would like to acknowledge the support of Research Grant No. Dean (R)/R\&D/2009/487, provided by University of Delhi, Delhi, India for conducting this research. The second author would like to thank University Grant Commission (UGC) for providing the fellowship to accomplish the research. 


\section{References}

Banerjee, A. (1986). A joint economic lot size model for purchaser and vendor. Decision Sciences, 17(3), 292-311.

Ben-Daya, M., \& Hariga, M. (2004). Integrated single vendor single buyer model with stochastic demand and variable lead time. International Journal of Production Economics, 92, 75-80.

Ben-Daya, M., \& Raouf, A. (1999). Inventory models involving lead time as decision variable. Journal of the Operational Research Society, 45, 579-582.

Chang, H. C., Ouyang, L. Y., Wu, K. S., \& Ho, C. H. (2006). Integrated vendor-buyer cooperative inventory models with controllable lead time and ordering cost reduction. European Journal of Operational Research, 170(2), 481-495.

Cheng, T. L., Huang, C. K., \& Chen K. C. (2004). Inventory model involving lead time and setup cost as decision variables. Journal of Statistics and Management Systems, 7(1), 131-141.

Chuang B. R., Ouyang L. Y., \& Lin Y. J. (2004). A Minimax distribution free procedure for mixed inventory model with backorder discounts and variable lead time. Journal of Statistics and Management Systems, 7(1), 65-76.

Gallego, G., \& Moon, I. (1993). The Distribution Free Newsboy Problem: Review and Extensions. Journal of the Operational Research Society, 44, 825-834.

Goyal, S. K. (1976). An integrated inventory model for a single supplier-single customer problem. International Journal of Production Research, 15(1),107-111.

Goyal, S. K. (1995). A one-vendor multi-buyer integrated inventory model: a comment. European Journal of Operational Research, 82, 209-210.

Goyal, S.K., \& Nebebe, F. (2000). Determination of economic production-shipment policy for a single-vendor-single-buyer system. European Journal of Operational Research, 121, 175-178.

Ha, D., \& Kim, S. L. (1997). Implementation of JIT purchasing: An integrated approach. Production Planning and Control, 8(2), 152-157.

Hariga, M., \& Ben-daya, M. (1999). Some stochastic inventory models with deterministic variable lead time. European Journal of Operational Research, 113, 42-51.

Hill, R. M. (1999). The optimal production and shipment policy for the single-vendor single-buyer integrated production inventory problem. International Journal of Production Research, 37 (11), $2463-2475$.

Hoque, M.A. (2007). An alternative model for integrated vendor-buyer inventory under controllable lead time and its heuristic solution. International Journal of Systems Science, 38(6), 501-509.

Kim, K. L., Hayya, J. C., \& Hong, J. D. (1992). Setup reduction in economic production quantity model. Decision Sciences, 23, 500-508.

Liao, C. J., \& Shyu, C. H. (1991). An analytical determination of lead time with normal demand. International Journal of Operations \& Production Management, 11, 72-78.

Lin, Y. J. (2009). An integrated vendor-buyer inventory model with backorder price discount and effective investment to reduce ordering cost. Computers and Industrial Engineering, 56, 15971606.

Lu, L. (1995). A one-vendor multi-buyer integrated inventory model. European Journal of Operational Research, 81, 312-323.

Moon, I., \& Choi, S. (1998). A note on lead time and distributional assumptions in continuous review inventory models. Computers \& Operations Research, 25, 1007-1012.

Nasri, F., Affisco, J. F., \& Paknejad, M. J. (1990). Setup cost reduction in an inventory model with finite range stochastic lead times. International Journal of Production Research, 28, 199-212.

Nori, V. S., \& Sarker B. R. (1996). Cyclic Scheduling for a multi product, single facility production system operating under a Just-in-time productions system. Journal of the Operational Research Society, 47, 930-935.

Ouyang L.Y., Wu K. S., \& Ho, C. H. (2007). An integrated vendor -buyer inventory model with quality improvement and lead time reduction. International Journal of Production Economics, 108, 349-358. 
Porteus, E. L. (1985). Investing in reduced setups in the EOQ model. Management Sciences, 31, 9981010.

Sarker B. R., \& Coates E. R. (1990). Manufacturing setup cost reduction under variable lead times and finite opportunities for investment. International Journal of Production Economics, 49, 237 247.

Silver, E. A., \& Peterson, R. (1985). Decision Systems for Inventory Management and Production Planning. New York: John Wiley.

Tersine, R. J. (1994). Principles of Inventory and Materials Management. New Jersey: PTR Prentice Hall, Englewood Cliffs.

Trevino, J., Hurley, B. J., \& Friedrich, W. (1993). A mathematical model for the economic justification of setup time reduction. International Journal of Production Research, 31, 191-202.

Yang, J. S., \& Pan, J. C. (2004). Just-in-time purchasing: an integrated inventory model involving deterministic variable lead time and quality improvement investment. International Journal of Production Research, 42 (5), 853-863. 